\title{
PERANCANGAN STASIUN TANAH ABANG DENGAN METODE TRANSIT ORIENTED DEVELOPMENT (TOD)
}

\author{
Mustofa $^{1}$, Karya Widyawati ${ }^{2}$, Indah Yuliasari ${ }^{3}$ \\ ${ }^{1}$ Universitas Indraprasta PGRI, Program Studi Arsitektur \\ emus39@gmail.com \\ ${ }^{2}$ Universitas Indraprasta PGRI, Program Studi Arsitektur \\ karya.widyawati@unindra.ac.id \\ ${ }^{3}$ Universitas Indraprasta PGRI, Program Studi Arsitektur \\ indah.yuliasari@unindra.ac.id
}

\begin{abstract}
Purpose Design of stations with designs connected to several modes of transportation that can support the achievement of travel and activity centers. Tanah Abang Station is a large station in Jakarta with a central area of primary activity and is a transit station that connects Tanggerang, Bogor and Central Jakarta. Annual passenger growth continues to grow and the development of transportation systems in Jakarta such as; MRT, LRT, and KA - airport, demanding that the service of the transportation system at Tanah Abang station be fulfilled for the people who use railroad services. The method used in this study uses qualitative methods. Development with a transit oriented system with the Transit Oriented Development (TOD) method is the concept of integrated system development with other mass transportation modes in order to accelerate transit times and support community mobility towards offices and other centers of economic activity.
\end{abstract}

Key Words: Design, Tanah Abang Station, Transportation, TOD

\begin{abstract}
Abstrak. Tujuan Perancangan stasiun dengan desain terkoneksi dengan beberapa moda transportasi yang dapat mendukung dalam pencapaian perjalanan dan pusat aktivitas. Stasiun Tanah Abang merupakan stasiun besar di Jakarta dengan kawasan pusat kegiatan primer dan merupakan stasiun transit yang menghubungkan kota Tanggerang, Bogor dan Jakarta Pusat. Pertumbuhan penumpang yang setiap tahunnya terus bertambah dan perkembangan sistem transportasi di Jakarta seperti; MRT, LRT, dan KA - bandara, menuntut pelayanan sistem transportasi di stasiun Tanah Abang dapat terpenuhi bagi masyarakat pengguna jasa kereta api. Metode yang digunakan dalam penelitian ini menggunakan metode kualitatif. Pengembangan dengan sistem beroientasi transit dengan metode Transit Oriented Development (TOD) adalah konsep pengembangan sistem terintergrasi dengan moda transportasi masal lainya agar dapat mempercepat waktu transit dan menunjang mobilitas masyarakat menuju perkantoran dan pusat kegiatan ekonomi lainnya.
\end{abstract}

Kata Kunci : Perancangan, Stasiun Tanah Abang, Transportasi, TOD

\section{PENDAHULUAN}

Perkembangan kota Jakarta sebagai ibu kota dengan pusat perekonomian di Indonesia sudah seharusnya sejajar dengan kota-kota besar di dunia. Dengan pertumbuhan ekonomi dan penduduk di tiap tahunnya, menjadikan Kota Jakarta tersibuk di Indonesia. Di Jakarta setiap harinya lebih dari 4 juta penumpang dari daerah sekitar DKI Jakarta ( Jabodetabek ) keluar dan masuk wilayah Jakarta tersebut. Kecenderungan perluasan Kota Jakarta yang begitu tinggi dan kurang terkontrol secara signifikan dapat meningkatkan biaya transportasi, mengurangi tingkat mobilitas dan menurunkan kualitas hidup.
Persoalan kemacetan menjadi masalah besar di Kota Jakarta. Akibat kemacetan ini berdampak pada lingkungan, sosial dan ekonomi Kota Jakarta. Belum lagi pemborosan energi dan pencemaran udara yang dihasilkan. Salah satu upaya dalam mengurangi kemacetan di Jakarta adalah dengan penyediaan stasiun transit yang terkoneksi dengan beberapa moda transportasi umum lainya, seperti Busway,LRT, MRT, Bus kota dan Angkutan Umum lainnya.

Stasiun Tanah Abang merupakan salah satu stasiun besar di Jakarta dengan kepadatan penumpang yang terus mengalami kenaikan setiap tahunnya. Terletak di kawasan kegiatan primer, yaitu kawasan pusat grosir tekstil terbesar di 
Indonesia, Stasiun Tanah Abang juga sebagai stasiun transit yang menghubungkan Wilayah Tangerang dan Jakarta Pusat. Dengan kondisi existing peron yang sudah tidak dapat menampung jumlah penumpang, maka perlu dilakukan konsep perancangan baru dalam pengembangan dan peremajaan Stasiun Tanah Abang.

Perancangan stasiun dengan desain terkoneksi dengan beberapa moda transportasi yang dapat mendukung dalam pencapaian tujuan perjalanan dan pusat aktivitas diharapkan dapat memberi solusi dan dapat mengubah pola pikir masyarakat dalam penggunaan transportasi umum dari pada menggunakan kendaraan pribadi. Kebutuhan masyarakat akan kemudahan layanan transportasi dan mobilitas yang tinggi di kawasan Tanah Abang menjadi tuntutan dalam pelayanan dan penyediaan fasilitas transportasi yang dapat memberikan kualitas kenyamanan,keamanan dan jarak waktu tempuh yang singkat dalam pencapaian ke pusat pusat aktivitas masyarakat.

\section{METODOLOGI}

Metode yang digunakan dalam penelitian ini menggunakan metode kualitatif. Metode ini berupa penelitian yang menghasilkan data deskriptif berupa kata tertulis/lisan dari orangorang atau perilaku yang dapat diamati dengan menggunakan pendekatan deduktif.

Metode ini dalam pendekatan perencanaan adalah sebagai acuan untuk menyusun landasan perencanaan dan progam perencanaan Stasiun Tanah Abang, diantaranya ;

a. Pengumpulan data primer, meliputi ;

- Rencana Tata Ruang dan Wilayah (RTRW) Jakarta 2030 mengenai wilayah stasiun Tanah Abang sebagai pusat kegiatan primer.

- Studi literatur tentang pengembangan kawasan Transit Oriented Development.

- Rencana Pemerintah dalam pengembangan Stasiun Tanah Abang di masa depan dalam sebagai kawasan TOD.

b. Pengumpulan data sekunder, antara lain;
- Studi banding atau presedent arsitektur mengenai perencanaan proyek stasiun sejenis.

- Pengamatan langsung permasalahan di lapangan mengenai permasalahan yang terjadi saat ini di stasiun Tanah Abang.

- Pemanfaatan maksimal potensi di sekitar stasiun Tanah Abang..

- Pengamatan tentang perkembangan transportasi umum di Jakarta saat ini.

- Menganalisa perilaku kegiatan masyarakat perkotaan dalam menggunakan transportasi umum.

\section{HASIL DAN PEMBAHASAN Pengertian dan manfaat TOD}

Menurut Kamus Besar Bahasa Indonesia (KBBI) stasiun adalah tempat menunggu bagi calon penumpang kereta api atau sebagainya. Disebut juga tempat pemberangkatan dan pemberhentian kereta api. Bangunan Stasiun Kereta Api sendiri berarti bangunan untuk keperluan operasional kereta api yang terdiri dari gedung, instalasi pendukung dan peron.

Transit Oriented Development (TOD) merupakan suatu strategi pengembangan suatu kawasan yang padat dengan tata guna lahan campuran (mix-use) dengan berfokus pada stasiun transit (bus atau kereta api).

Dalam wilayah TOD dapat di masukkan area sekunder yang berfungsi sebagai tempat pemberhentian untuk menunjang kegiatan perpindahan transportasi yang ada (Transit dan transfer). Titik sekunder ini berada pada daerah pengembangan TOD dan tidak jauh dari pusat area komersil yang ada.Titik transit sekunder ini berada pada area yang harus mudah di akses dari titik transportasi kota maupun dari dalam area pengembangan TOD.

Pada prinsipnya konsep TOD pada perancangan stasiun bertujuan untuk memberi alternative dan pemecahan bagi permasalahan dan pertumbuhan penumpang pengguna jasa kereta api yang cenderung pada permasalahan sprawling/pemekaran. Dengan membuat sistem yang saling terkoneksi dan dalam jangkauan 
pejalan kaki dengan waktu jarak tempuh kurang dari 15 menit untuk berpindah pada moda transportasi dan mencapai titik pusat kegiatan komersil maupun perkantoran. Akumulasi pola transit ini diharapkan dapat memberi solusi dalam sistem transportasi di wilayah subkota Jakarta.

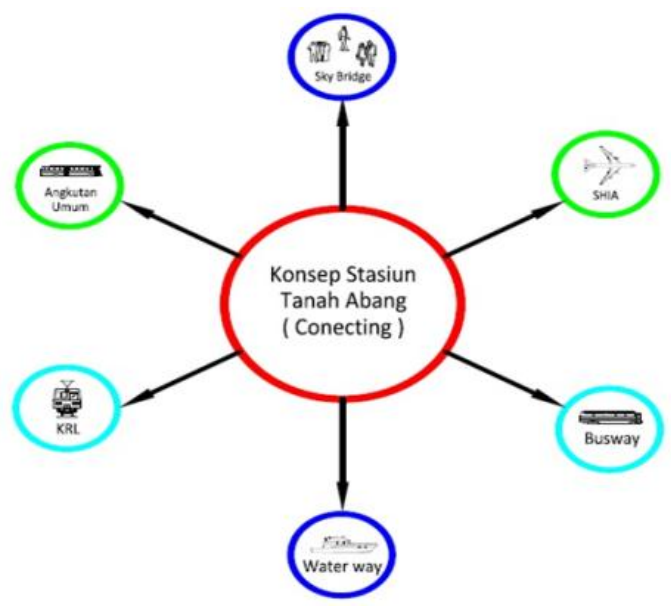

Gambar 1. Prinsip perancangan konsep TOD

Mengacu kepada perda No.1 tahun 2012 tentang Rencana Tata Ruang Wilayah DKI Jakarta 2030, konsep TOD merupakan bagian dan rencana pembangunan tata ruang wilayah DKI Jakarta di masa depan. Mengutip pasal 84 Perda No.1 Tahun 2012 pengembangan kawasan Transit Oriented Development (TOD) dilakukan di terminal / stasiun antar moda di pusat kegiatan,stasiun,shelter dan terminal angkutan umum massal yang terintregrasi dengan daerah sekitarnya. Kawasan Transit Oriented Development (TOD) merupakan kawasan campuran pemukiman dan komersil dengan aksebilitas tinggi terhadap angkutan umum masal,dimana stasiun angkutan umum massal dan terminal angkutan umum massal sebagai pusat kawasan dengan bangunan berkepadatan tinggi. Lokasi terminal / stasiun dengan konsep TOD ditetapkan di kawasan sebagai berikut ;

a. Perpotongan koridor angkutan massal ( dua atau lebih ) ; kawasan dengan nilai ekonomi tinggi atau yang diprediksikan akan memiliki nilai ekonomi tinggi ; dan

b. Kawasan yang direncanakan atau ditetapkan sebagai pusat kegiatan.
Rencana pengembangan pusat - pusat kegiatan wilayah DKI Jakarta ditunjukan dalam gambar dibawah ini ;

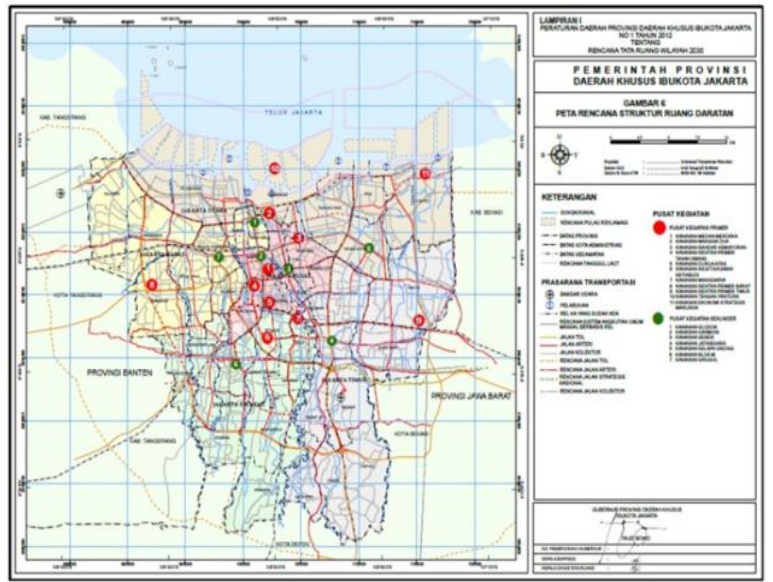

Gambar 2. Peta Tanah Abang sebagai kegiatan Primer

Adapun tujuan dalam perancangan stasiun dengan sistem TOD antara lain adalah:

a. Mempercepat aksebilitas masyarakat dalam mencapai titik titik komersil di kawasan Tanah Abang.

b. Meningkatkan mobilitas dalam mendukung kemajuan kota yang produktif.

c. Diharapkan dapat merubah pola pikir masyarakat untuk lebih banyak menggunakan kendaraan umum dari pada kendaraan pribadi.

d. Ikut berperan serta meningkatkan kualitas layanan publik terutama dalam bidang pelayanan transportasi.

e. Mendapatkan landasan dasar yang baru dalam perancangan sebuah stasiun yang mampu memberikan solusi terhadap masalah yang ada.

Beberapa manfaat perancangan stasiun dengan konsep TOD ini yaitu ;

a. Meningkatkan aksebilitas dan mobilitas masyarakat kota dan kawasan disekitarnya.

b. Mengurangi ketergantungan masyarakat terhadap penggunaan kendaraan pribadi.

c. Sebagai referensi desain dalam perancangan sebuah stasiun.

d. Mengurangi kemacetan lalu lintas di kawasan atau di sekitar lokasi stasiun.

e. Efektif dalam waktu dan biaya dalam melakukan perjalanan.

f. Meningkatkan pertumbuhan ekonomi dan pengambangan kawasan di sekitar. 
g. Meningkatkan kualitas udara bersih dengan pengurangan penggunaan kendaraan pribadi.

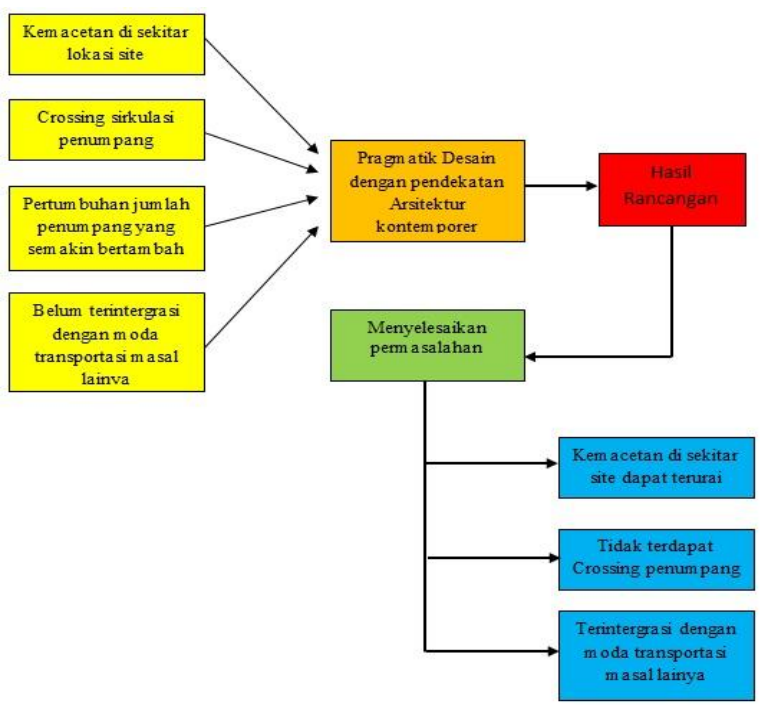

Gambar 3. Skema Metode Perancangan

\section{Konteks Urban}

Berdasarkan RTRW Jakarta Tahun 2030 kecamatan Kampung Bali - Tanah Abang merupakan bagian wilayah Kota Jakarta Pusat yang sedang berkembang dan sebagai pusat kegiatan perekonomian seperti perdagangan,jasa dan perkantoran. Dalam visinya disebutkan bagian Jakarta Pusat peruntukannya digunakan untuk kawasan pusat niaga terpadu,dalam kawasan skala nasional dan internasional. Nantinya kawasan Tanah Abang akan menjadi kawasan sentra bisnis baru. Untuk mendukung pengembangan sentra bisnis baru ,maka sarana transportasi di stasiun Tanah Abang perlu di adakan pengembangan menjadi stasiun terpadu dengan sistem Transit Oriented Development TOD. Stasiun ini nantinya akan terhubung dengan beberapa moda transportsai masal lainya seperti ;Busway,Kereta Bandara,Water Way, dan angkutan kota lainya.

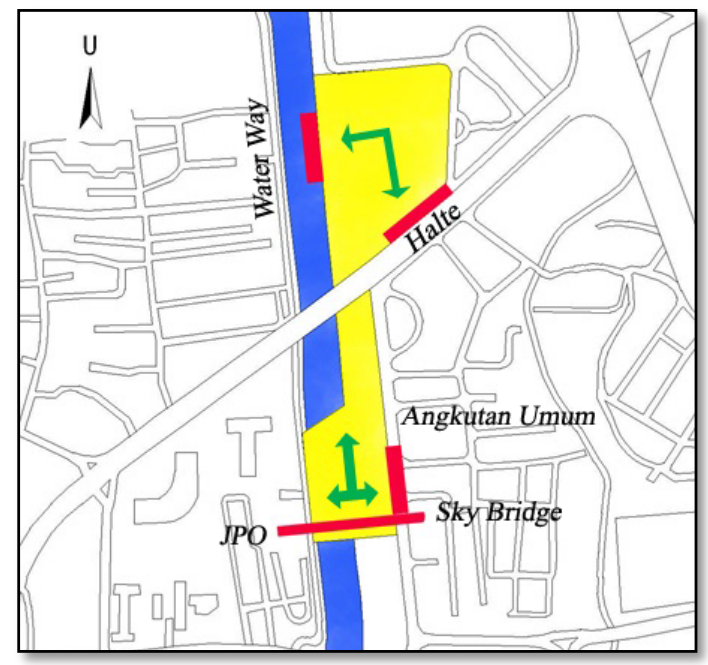

Gambar 4. Konsep Conecting

Beberapa fungsi dari Stasiun Tanah Abang adalah sebagai berikut :

a. Sebagai stasiun transit dari kota penyangga DKI Jakarta seperti Tanggerang, Bogor, Rangkas Bitung, Maja, Bintaro,Jatinegara dll

b. Sebagai stasiun akhir tujuan untuk melakukan kegiatan perniagaan di kawasan pasar Tanah Abang.

c. Sebagai pusat konektifitas yang menghubungkan beberapa moda transportasi.

\section{Pemakai}

Pengguna stasiun Tanah Abang adalah sebagai berikut :

a. Penumpang dengan kepentingan bekerja di sekitar kawasan stasiun.

b. Pedagang yang memiliki toko di kawasan pasar tanah abang.

c. Pembeli yang mengakses pasar tanah abang melalui jalur kereta.

d. Pengguna dengan difabilitas yang ingin menuju pasar tanah abang.

e. Masyarakat sekitar yang bersekolah menggunakan moda transportasi kereta.

f. Penumpang yang melalui transit stasiun tanah abang yang menuju tanggerang.

g. Penumpang dengan tujuan bandara soekarno hatta. 
Adapun jenis kereta yang melalui stasiun Tanah Abang adalah sebagai berikut ;

a. KRL tujuan Bogor - Duri, Angke dan Jatinegara.

b. KRL tujuan Tanah Abang - Rangkas Bitung Tanggerang.

c. KRL Bandara Soetta / SHIA

d. Kereta lokomotif menuju Dipo.

\section{Analisis Tapak}

Letak Stasiun Tanah Abang ; $6^{\circ} 11^{\prime} 08^{~ “ ~ S ~} 106^{\circ} 48^{\prime}$ 38 " E

Ketinggian tanah 0-9 meter di atas permukaan air laut . Pada kawasan Tanah abang topografi cenderung rata namun elevasi stasiun lebih rendah dari tinggi permukaan sungai kanal banjir barat.

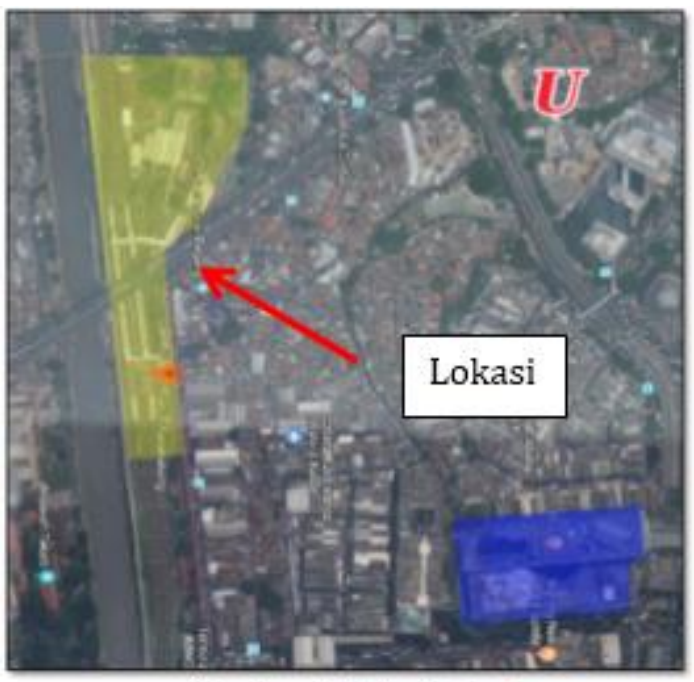

Gambar 5. Foto Lokasi

Jl. Jati Baru Raya, Cideng, Tanah Abang, Kota Jakarta Pusat, Daerah Khusus Ibukota Jakarta 10250, Indonesia

a. Dasar pemilihan lokasi adalah tanah abang merupakan salah satu stasiun besar di jakarta dengan tingkat kepadatan yang tinggi.

b. Merupakan pusat kawasan kegiatan primer dalam RTRW Jakarta tahun 2030.

Batasan ;

a. Utara : Fly over Jln. Jati Baru Raya Dipo Lokomotif Tanah abang

b. Selatan : Jln. Ks. Tubun, jln. Kebon jati

c. Barat : Jln. Jati Baru Raya Pasar Tanah abang Blok E

d. Timur : Jln. Tenaga Listrik, Sungai Kanal banjir barat
Menurut Peraturan daerah propinsi DKI No.1 Tahun 2014 tentang RTRW dan peraturan Zonasi ditetapkan ;

- Luas Lahan $\quad ; 29.880 \mathrm{~m} 2$

- KDB ;60\%

- Luas lantai dasar $\quad ; 40 \%$ x 29.880 $=19.920$ $\mathrm{m} 2$

- KLB ;2,40

- $\quad$ Luas Lantai Max. $\quad$; 4 x $19.920=79.680$ m2

\section{Analisa Pencapaian}

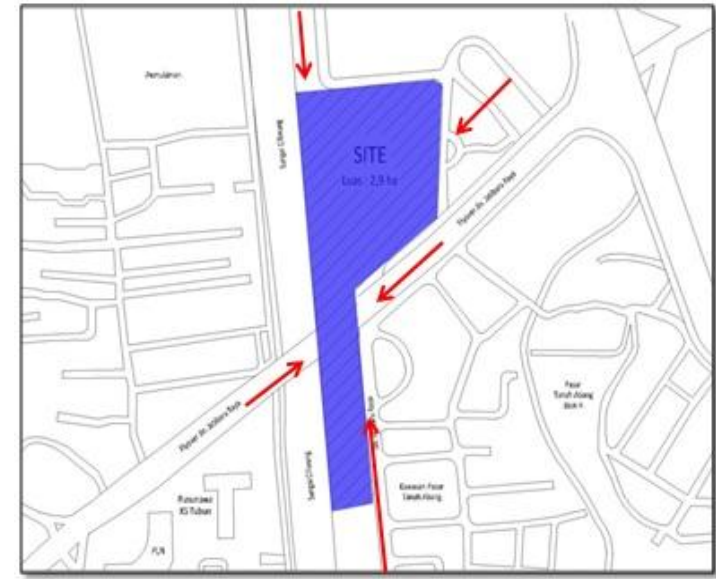

Gambar 6. Pencapaian

Pencapaian dari site existing dapat di tempuh melalui ;

- Dari sebelah selatan yaitu dari Jalan Kebon Jati dan Jalan Aibda KS. Tubun

- Dari arah timur bisa di capai melalui Jalan Jati raya,

- Dari arah utara yaitu melalui fly over Jln. Jati Baru raya .

\section{Sirkulasi}

Dalam perancangan stasiun ini, konsep sirkulasi secara garis besar dibagi menjadi 2 lapis, yaitu pada lantai 1; area penerimaan dan area sirkulasi pada peron, sedangkan pada lantai 2 dikhususkan hanya sebagai area transit atau "conecting". 

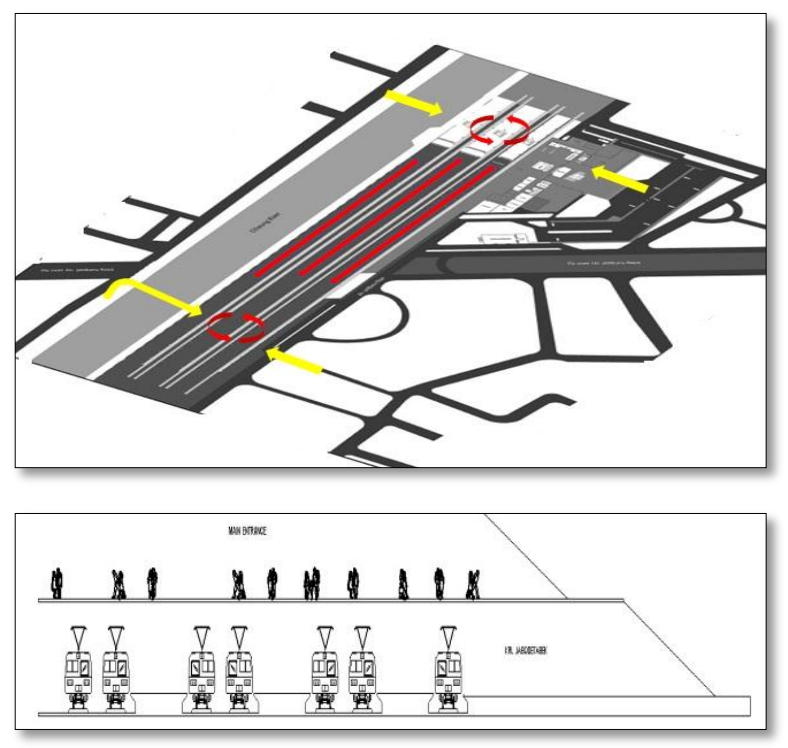

Gambar 7. Sirkulasi

\section{Analisa Angin / Penghawaan alami}

Angin pada tapak paling besar berasal dari arah barat menuju timur, yaitu dari jln. KS tubun menuju arah kanal banjir barat. Hal ini dimanfaat kan dalam menentukan bukaan peron pada area tunggu kereta api.
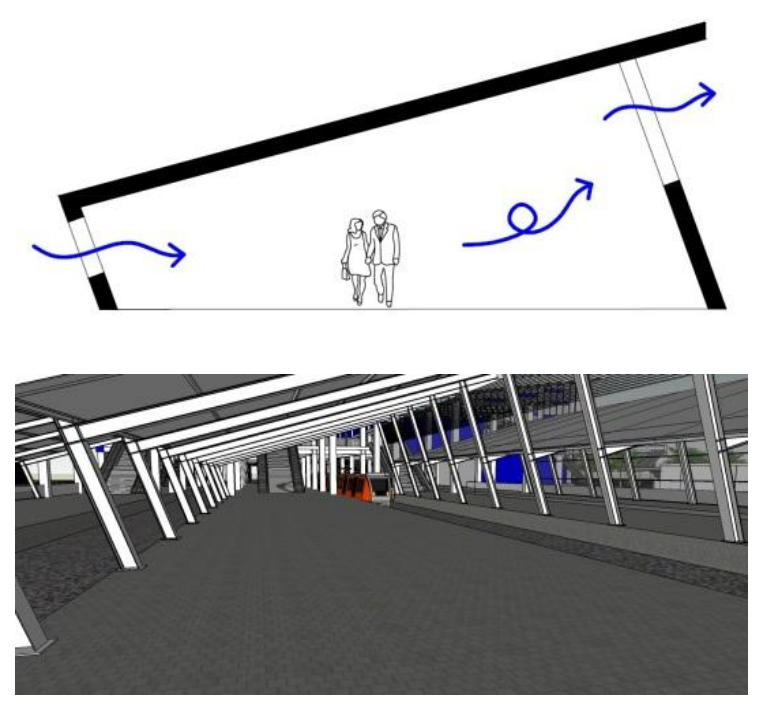

Gambar 8. Penghawaan alami pada peron

\section{Pencahayaan}

Pada area tapak cahaya matahari penuh dirasakan pada pagi sampai siang hari, sedangkan pada sore hari cahaya matahari cenderung redup karena terhalang beberapa bangunan di area timur tapak. Hal ini dimanfaatkan pada bukaan pencahayaan alami pada peron dan area transit pada lantai 2, agar dapat meminimalisir penggunaan cahaya buatan dari lampu sehingga berperan dalam penghematan energi listrik.
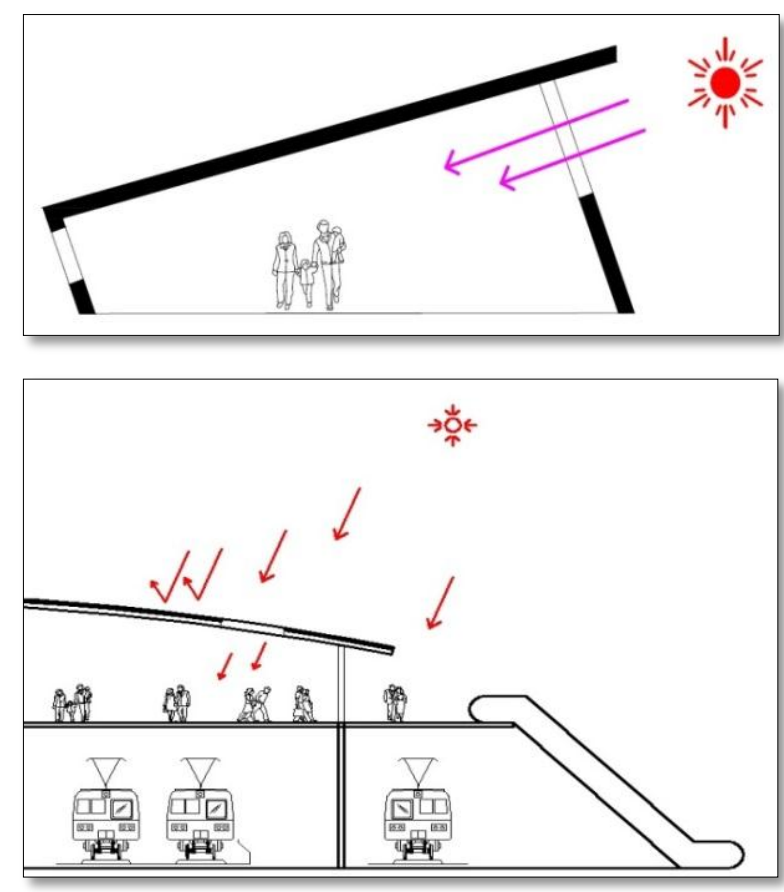

Gambar 9. Konsep pencahayaan alami

\section{Zonasi}

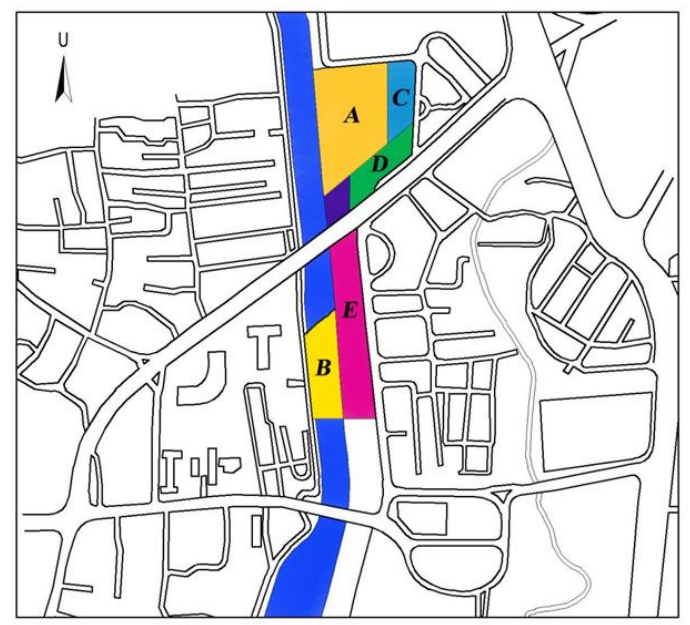

Gambar 10. Zonasi

Keterangan :

- $\mathbf{A}=$ Lobby Utama

- $\quad \mathbf{B}=$ Lobby Selatan

- $\quad \mathbf{C}=$ Entrance

- $\quad \mathbf{D}=$ Transit Area

- $\mathbf{E}=$ Peron Kereta 


\section{Desain}

1) Site Plan

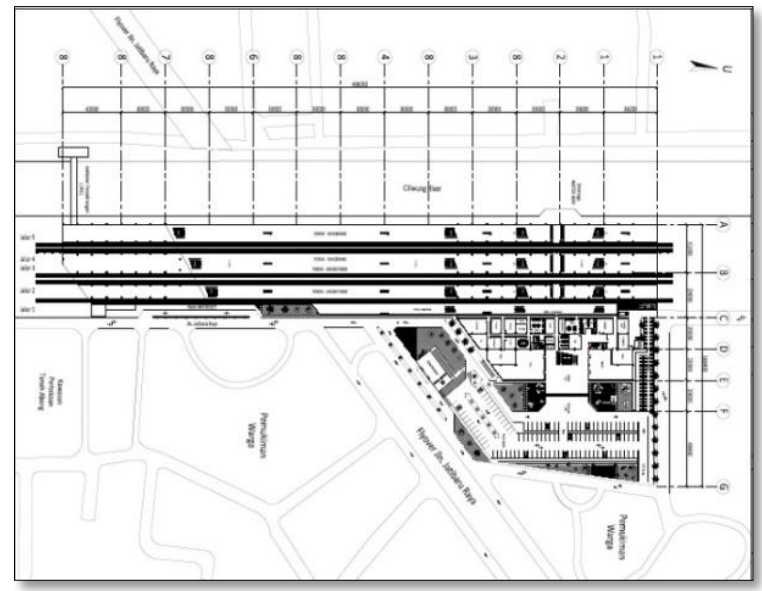

Gambar 11. Site Plan

2) Denah

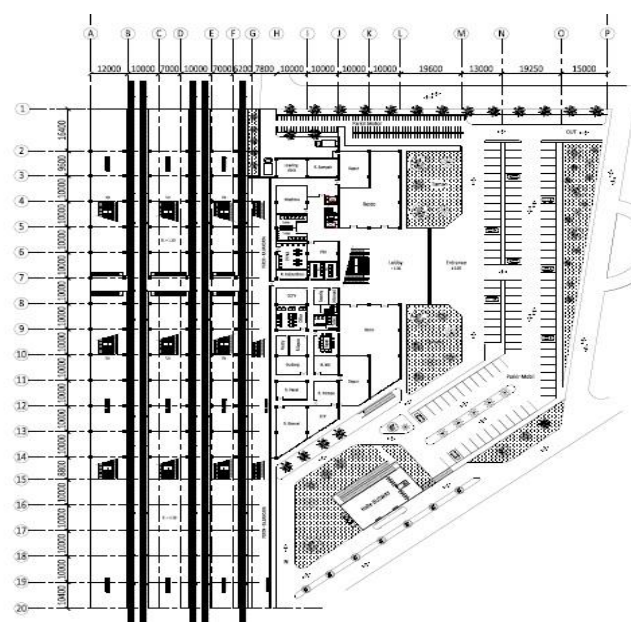

Gambar 12. Denah Bangunan Utama

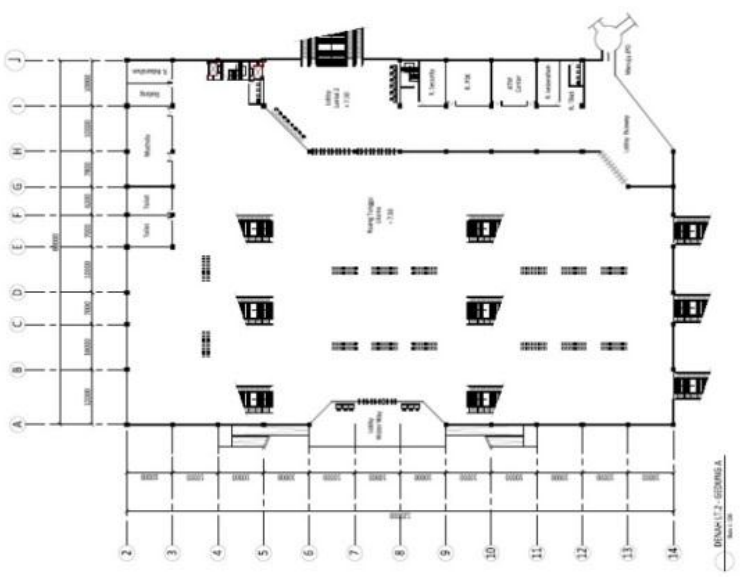

Gambar 13. Denah area transit

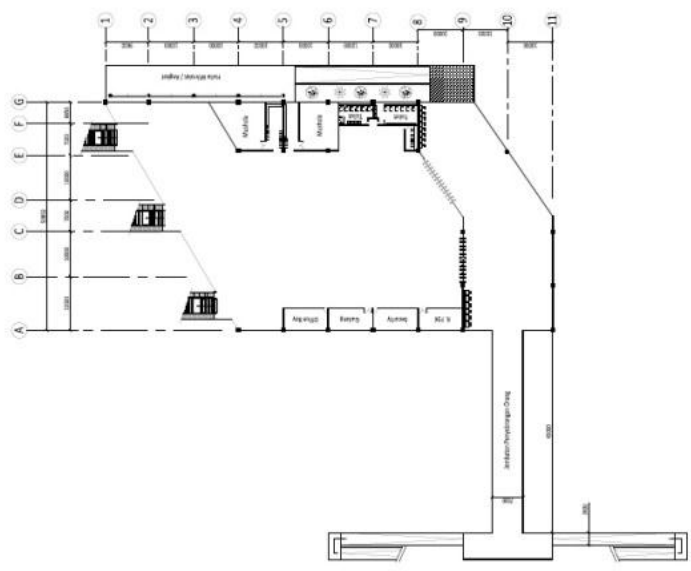

Gambar 14. Denah bangunan pendukung

3) Perspektif

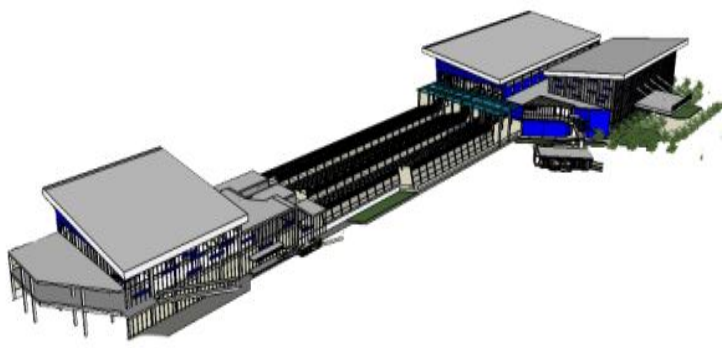

Gambar 15. Perspektif

4) Fasad \& Interior bangunan
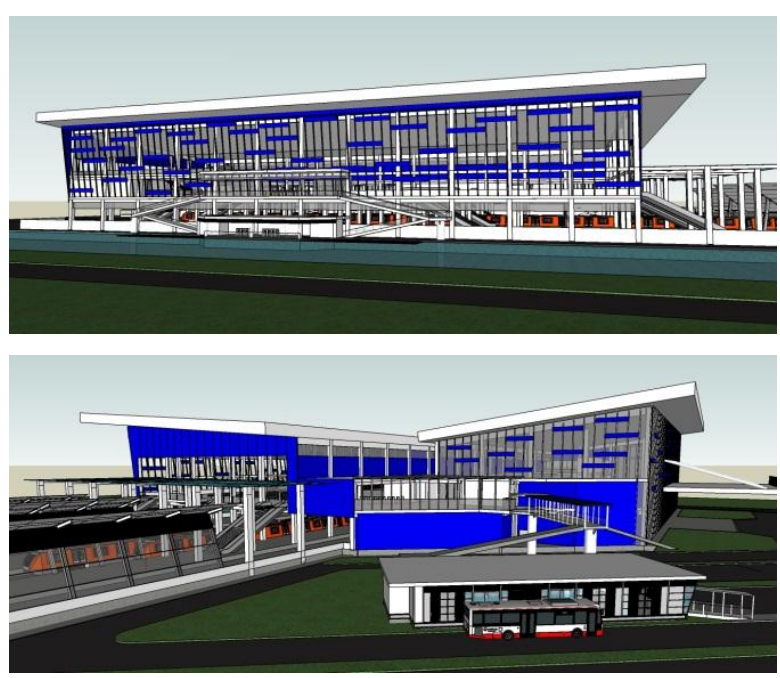

Gambar 16. Fasad Bangunan 


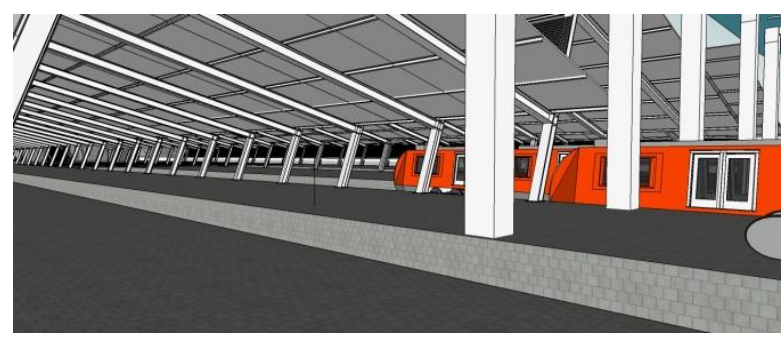

Gambar 17. Peron dan Conecting area
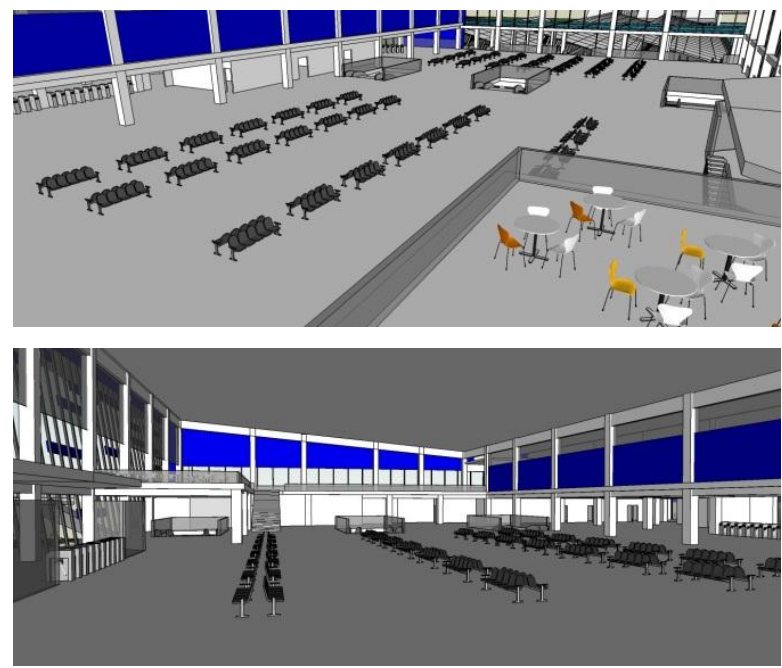

Gambar 18. Interior

\section{PENUTUP}

\section{Simpulan}

Perancangan stasiun Tanah Abang dengan system Transit oriented Development (TOD) diharapkan dapat menjadi infrastruktur yang dapat membantu dan memberi manfaat serta memberi kenyaman,keamanan, dan kemudahan kepada masyarakat pengguna jasa angkutan umum khususnya kereta api.

\section{Saran}

Diharapkan untuk kedepannya penelitian di setiap stasiun di jabodetabek dengan menggunakan sistem Transit Oriented Development (TOD) dapat ilaksanakan dan diwujudkan secara nyata.

\section{DAFTAR PUSTAKA}

Despacio. 2014. TOD Standart. Institute for Transportation \& Development Policy. Climate Work foundation ; New York

Alviansyah. 2016. Penerapan Konsep TOD sebagai Instrument Penguatan jaringan Angkutan Massal Perkotaan. Indonesia Urban Transport Institute ; Jakarta

Toding Kosmas, Jinca Yamin, Wunas Shirly . 2015. Sistem Transit Oriented Development (TOD) Perkeretaapian dalam Rencana Jaringan Kereta Api Komuter Mamminasata. Teknik Transportasi Pasca Sarjana Universitas Hasanuddin ; Makasar.

Dewi Marta Ketut. 2016. Penerapan TOD (Transit Oriented Development) sebagai upaya Mewujudkan Transportasi yang Berkelanjutan. Institut Teknologi Sepuluh November; Surabaya

Peraturan Daerah Propinsi daerah Khusus Ibukota Jakarta No.1 Tahun 2012. Rencana Tata Ruang Wilayah 2030; Jakarta

ArsDaily.2018. The Flinders Street Station https://www.archdaily.com/413924/the-

flinders-street-station-winning-proposaleduardo-velasquez-manuel-pineda-santiagomedina. Diakses November 2018

ArsDaily. 2018. Hangzhou East Railway Station https://www.archdaily.com/search/projects/ca tegories/trainstation?ad name=flyout\&ad me dium=categories. Diakses Desember 2018 